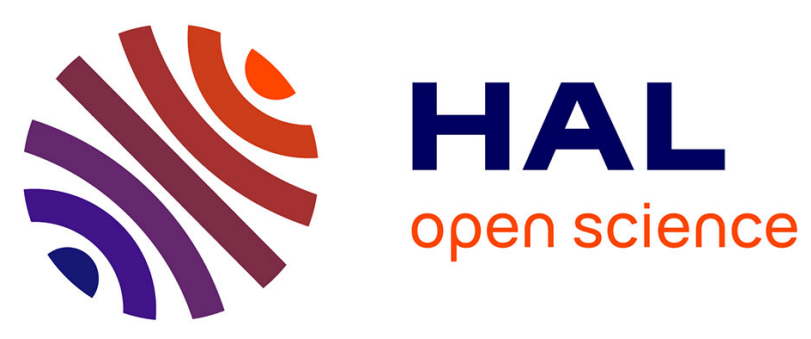

\title{
Formulating logistics strategy
}

Nathalie Fabbe-Costes, Jacques Colin

\section{To cite this version:}

Nathalie Fabbe-Costes, Jacques Colin. Formulating logistics strategy. James Cooper. Logistic and distribution planning: strategies for management, Kogan Page Limited, pp.36-50, 1994, 0-7494-0948-7. hal-01294176

\section{HAL Id: hal-01294176 \\ https://hal.science/hal-01294176}

Submitted on 1 Jan 2017

HAL is a multi-disciplinary open access archive for the deposit and dissemination of scientific research documents, whether they are published or not. The documents may come from teaching and research institutions in France or abroad, or from public or private research centers.
L'archive ouverte pluridisciplinaire HAL, est destinée au dépôt et à la diffusion de documents scientifiques de niveau recherche, publiés ou non, émanant des établissements d'enseignement et de recherche français ou étrangers, des laboratoires publics ou privés. 


\section{LOGISTICS 然 DISTRIBUTION PLANNING Strategies for Management}

Second edition

Edited by James Cooper

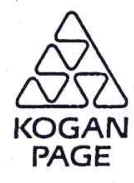




\section{Contents}

List of Contributors

Introduction

James Cooper

1. New Direction in Logistics

Martin Christopher

2. Assessing the Cost of Customer Service

Gordon V Hill

3. Formulating Logistics Strategy

Nathalie Fabbe-Costes and Jacques Colin

4. Organizing for Logistics

Philip Schary

First published in 1988

Revised edition 1990

5. Beyond the Logistics Pipeline: Opportunities for Competitive Advantage

Second edition

Apart from any fair dealing for the purposes of research or private study, or criticism or review, as permitted under the Copyright, Designs and Patents Act, 1988, this

publication may only be reproduced, stored or transmitted, in any form or by any means, with the prior permission in writing of the publishers, or in the case of reprographic

reproduction in accordance with the terms of licences issued by the Copyright Licensing Agency. Enquiries concerning reproduction outside those terms should be sent to the publishers at the undermentioned address:

Kogan Page Limited

120 Pentonville Road

London N1 9JN

(C) James Cooper, 1994

British Library Cataloguing in Publication Data

A CIP record for this book is available from the British Library.

ISBN 0749409487

Typeset by DP Photosetting, Aylesbury, Bucks

Printed and bound in Great Britain by

Biddles Ltd, Guildford and King's Lynn

6. The Global Logistics Challenge James Cooper.

Logistics Strategies for Europe

Michael Brown and Julian Allen

8. Logistics Strategies for the USA

Bernard $J$ La Londe and James M Masters

9. Logistics Strategies in Japan

Minoru Saito

10. Environmental Concern: Implications for Supply Chain Management

Ivy Penman

11. Planning the Location of Depots

C D T Watson-Gandy

12. Making Warehouses Work More Efficiently John Oxley

13. Distribution Round the Clock James Cooper and Geoff Tweddle 
Chapter 3

\section{Formulating Logistics Strategy}

\author{
Nathalie Fabbe-Costes and Jacques Colin \\ CRET
}

University of Aix-Marseille II

\section{Why Formulate Logistics Strategies?}

Commercial and industrial organizations can be thought of as systems which are composed of operational processes structured and regulated by a set of functions that can become strategic; they are currently the object of intense environmental pressures. Never have these forces been so diverse: they are disrupting previous equilibriums and call for rapid and coherent responses, as shown in Figure 3.1.

The multiplicity of corporate responses implies coordination and integration in an approach with a clearly defined strategic character. Indeed, only through the use of strategy, this 'art of using information

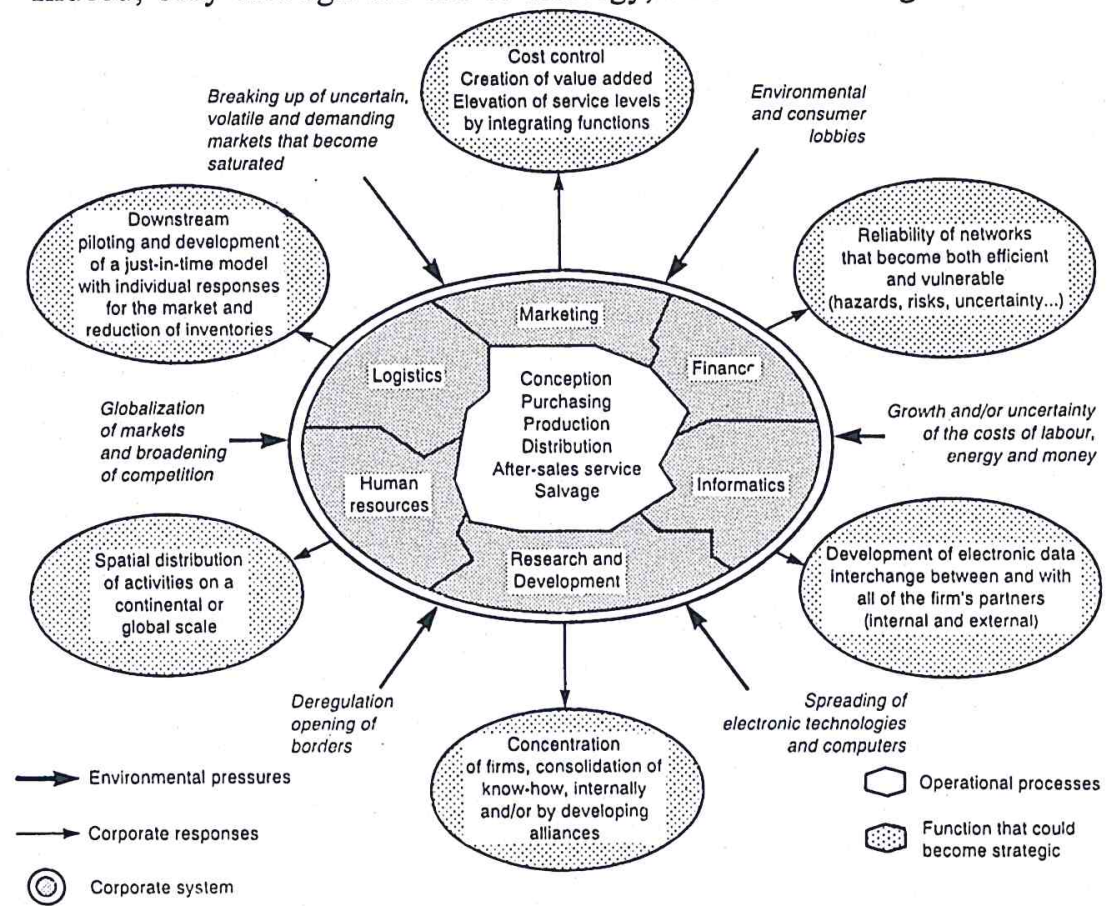

(C) Corporate system

Figure 3.1 Corporate responses to environmental pressures obtained in operating, integrating it, quickly formulating plans of action and having the ability to gather a maximum of certainties in order to confront the uncertain, will companies be able to overcome the extreme environmental instability that appears to be characterizing the end of the millennium. Strategy will enable companies to formulate and achieve their objectives, allowing them to seize and take advantage of opportunities as they arise, while, at the same time, remaining in tune with their environment.

It appears that one of the priorities that is considered essential today by numerous firms is an understanding of logistics. Logistics, defined as the technology of control of the physical flow of materials and goods and related information that a firm sends, transfers and receives, appears as an organizational approach that can conserve and improve the flexibility and reactivity of the firm vis-à-vis its environment.

In order to satisfy its ideal objectives of continuity (preventing stockout) and fluidity (limiting overcapacity), logistics has progressively left behind its original operational role, which was a combination of transport, handling and warehousing operations. The concept of a logistics chain enabled firms to control flow from downstream to upstream and to optimize, in terms of cost and level of service, the whole physical movement pulled by demand. The field of logistics has therefore been considerably broadening, as illustrated in Figure 3.2.

Logistics has now become a very far-reaching 'total' approach, which is both transversal and very ambitious. Its main role is to synchronize overall physical flow, and it is indeed in permanent interaction with all of the classic functions of a firm, constituting an active interface between the firm and its environment.

It is paradoxical to note that while the environmental pressures that appear in Figure 3.1 are not specific to logistics, the same cannot be said of the responses that firms in most sectors must now make. Their for-

\begin{tabular}{|l|l|lll|}
\hline & Distribution & & Salvage \\
\hline logistics
\end{tabular}

Source: Adapted from Mathe, H., Colin, J., Tixier, D., La logistique, Dunod, Paris, 1983. Figure 3.2 Evolution of the field of action of logistics 
mulation conceals options that imply a logistics approach, especially when responses are combined. For challenges that are not specifically logistic, the firm conceives solutions and strategies that are, or that become logistic.

The profound transformations that have taken place in the structure of firms, as well as the extension of their activities, have confirmed the need for a strategic approach to logistics. Its aim is to control the areas where the firm operates, the timing of these operations and finally, the inherent risks involved in the firm's choices.

How can one identify the strategic projects in which logistics could play a key role? To answer this question in a 'creative' manner, we thought it indispensable to propose an innovative approach to strategy formulation.

\section{A Conceptual Approach to Formulating Logistics Strategy}

The classic approach to formulating a logistics strategy consists in beginning with the firm's overall strategy and then defining the logistics strategy that will enable the firm to reach its objectives. Logistics is thus conceived as a functional support system and a tool for global strategy; logistics strategy should appear as a subset of the overall strategy. The control of the flow of materials and goods today constitutes a key factor for success in numerous domains which justifies this downward approach.

Logistics, like other functions such as marketing and informatics, also opens new strategic lines of action. In order to formulate these new lines, it is imperative to reverse the classic approach, to think strategic logistics rather than logistics strategy.

Strategic logistics consists in imagining and developing strategic actions that would be impossible without strong logistics competences. From being seen first as a key factor for success, logistics is becoming a fully competitive advantage. This viewpoint makes it necessary to think about logistics at the very moment when the overall strategy is being elaborated and to foresee how, in certain cases, it can be the very foundation of the strategic action.

The two interrelated perspectives between logistics and strategy shown in Figure 3.3 lead to very different formulations and to company projects that are also very different. It should be noted that they do not exclude each other, but correspond to distinct finalities. The principal differences are summarized in Table 3.1 .

The determining factor for 'reversing' the perspectives would seem to be the maturity of the perception of logistics as a cross-functional and deliberately open-ended management domain in the firm. Thus, the interactive loop between strategy and logistics is generally initiated by a request from strategy to logistics, historically centred on the control (reduction) of logistics costs.

The experience, know-how and systems developed in logistics action then retroact on the strategy, becoming the vector of its (re)formulation,

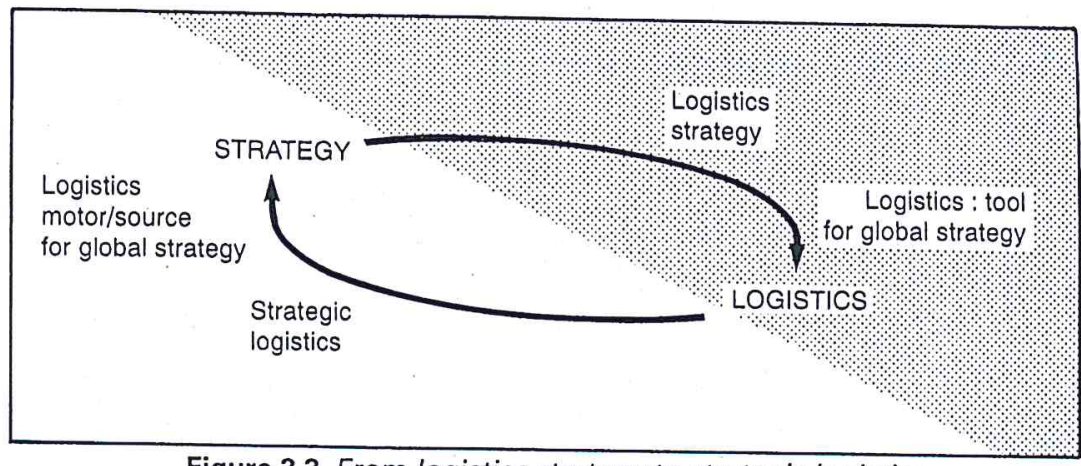

Figure 3.3 From logistics strategy to strategic logistics

enabling the firm to differentiate itself by the logistics services it provides, increasing its range of combined products and services, or even diversifying into logistics activities.

Finally, strategic logistics formulations emerge from this repeated transversing of the interactive strategy/logistics loop, which becomes a 'progress spiral'2 for the firm. The purpose of running through this loop is to have a logistics organization that is adapted to the firm's objectives, and to be able to identify, exploit, or even better, create opportunities for the firm.

The strategic formulation of logistics can be expressed by two 'classic' concepts of strategy: the profession and the mission. In concrete terms, to formulate a logistics strategy, one defines the ranges of movement that it 'produces', how it produces them (technologies, know-how, organization), to whom they are directed (internal or external clients) and the needs that they satisfy. Consequently, this formulation can identify several 'sectors of activity' that are more or less synergistic. Among them, some can be considered supports for the firm's overall strategy (logistics strategy perspective), while other sectors can be vectors of its strategy (strategic logistics perspective)

Formulation is then oriented to the choice of organizational solutions to adopt in order to achieve defined objectives. It should be noted that as a transversal function of coordination for all stages of movement and for management for both internal and external interfaces, logistics can only be efficient if it is linked with the other functions, rather than replacing them. Options that are chosen in the domain of logistics must in particular be congruent with those in the domains of marketing, finance, information systems, manufacturing and human resources. Ideally, logistics strategy should be combined with the other strategies, and

Table 3.1 Main differences between logistics strategy and strategic logistics

\begin{tabular}{lll}
\hline & Logistics strategy & Strategic logistics \\
\hline $\begin{array}{l}\text { Perception of logistics } \\
\text { stakes }\end{array}$ & strategy support & strategy foundation \\
\hline Effects on organization & improvement, evolution & change, transmutation
\end{tabular}


strategic logistics should use the levers that other functional domains represent.

At present, information-system management is the domain which has the strongest synergies with logistics. The coincidence of the emergence of strategic logistics and strategic informatics is certainly not accidental It can be explained by the overlapping of physical and informational circulation (the piloting concept), to which we could associate financial circulation. It could also be explained by the transversality and the outward opening of logistics and information communication systems, as well as by the dynamic character of the management processes that they support. In addition, the control of physical and informational flow develops and is the support for a flexibility and adaptability of the firm that is now indispensable for durability and growth.

The formulation of logistics strategy also deals with the 'make or buy' decision. The strategic or non-strategic character of a logistics organization provides information on the originality and confidentiality required for the necessary know-how, the expected reliability of the processes and the significance of the planned organization. In the cases of delegated operations or organizations, it brings about the definition of the means required to ensure control. It therefore creates networks of complementary skills and ensures their consistency.

It is not our intention, at this point, to go into existing organizations in detail. However, we do wish to illustrate through actual examples of logistics projects how firms have taken into account the strategic dimension of logistics.

\section{Illustrated Typology of Possible Logistics Strategies}

In order to specify and illustrate the conceptual approach to the strategic formulation of logistics, we have selected several case studies of distributors, manufacturers and genuine 'logistics firms' that have now become transporters and logistics suppliers. They represent a variety of strategies and are dealt with by category. Our typology, presented in Table 3.2, contains six 'classic' generic strategic axes and considers strategic formulations by adopting both perspectives described in Figure 3.3.

Certain axes correspond to actions conceived (at least initially) without changing the domain of activity (cost domination, differentiation and innovation), or imagined in order to move to new domains of activity (expansion and diversification), with alliance, a priori, allowing for both.

\section{Cost Domination}

Logistics Strategy: Reduce Costs That Are Specific To Logistics

- Becton-Dickinson, a multinational firm in the medical sector, has centralized its stock in a single European site in order to reduce its
Table 3.2 Typology of logistic strategies and strategic logistics

\begin{tabular}{lll}
\hline Approach & Logistics Strategy & Strategic Logistics \\
\hline Cost domination & Reduce logistics costs & $\begin{array}{l}\text { Reduce overall costs } \\
\text { with logistics }\end{array}$ \\
\hline Differentiation & $\begin{array}{l}\text { Quality of logistics } \\
\text { service }\end{array}$ & $\begin{array}{l}\text { Logistics factor of } \\
\text { differentiation }\end{array}$ \\
\hline Innovation & $\begin{array}{l}\text { Logistics support for } \\
\text { innovation }\end{array}$ & $\begin{array}{l}\text { Logistics as a source/ } \\
\text { motor for innovation }\end{array}$ \\
\hline Alliance & $\begin{array}{l}\text { Logistics as a means of } \\
\text { alliance }\end{array}$ & $\begin{array}{l}\text { Logistics as a source/ } \\
\text { motor for alliance }\end{array}$ \\
\hline \multicolumn{1}{c}{ Profession } & $\begin{array}{l}\text { Logistics as a support for } \\
\text { integration }\end{array}$ & $\begin{array}{l}\text { Logistics as a new } \\
\text { product }\end{array}$ \\
Expansion \\
Mission
\end{tabular}

inventory level and at the same time the financial costs of immobilized capital.

- After reducing the number of their factories and specializing the remaining ones at a European level (economies of scale on production costs), SKF and Roussel-UCLAF had to construct a distribution logistics scheme in order to control costs that threatened to soar.

- In order to limit the costs of stock possession, Bull distributed its stock of spare parts in a hierarchic network with local, national and European warehouses.

- Carrefour, a French hypermarket chain, gave up systematically supplying its stores directly from manufacturers; it now has products delivered to warehouses maintained by logistics suppliers in order to reduce the cost of supplying.

Strategic Logistics: Through Logistics, Reduce Overall Costs

- Auchan, a French hypermarket chain, has a network of warehouses, permitting it to considerably. reduce purchasing costs through the ability to stock massive quantities that it imports or buys on promotion from its suppliers.

- Intermarche, a French supermarket chain, works in the same manner: two-thirds of its inventory corresponds to a speculative stock of promotional products and products bought at a high discount for quantity.

- In the automobile industry, logistics approaches to external flow 
control by reducing the number of suppliers have succeeded in diminishing supply costs. Renault and PSA (Peugeot) now have only 950 primary suppliers who were all due to be registered (with stricter certification than ISO norms) in 1993 to deliver just-in-time. Qualitative and quantitative controls on delivery were to be totally eliminated.

\section{Differentiation}

Logistics Strategy: Improve the Quality of the Logistics Service

- By rationalizing their logistics, Becton-Dickinson and Bull were able to improve their performances in terms of quality of service, availability of references, complete deliveries, guaranteed delivery times.

- Mory-Protect, a French logistics supplier in the Novalliance group, has specialized in the logistics of dangerous products (chemical) and has become a recognized specialist.

- Philips-Eclairage has a highly automated central warehouse in the Paris area that is controlled by computerized logistics, making it possible to deliver to its clients every day. Thus wholesalers no longer need to hold more stock than is needed in between deliveries: they choose to be preferentially supplied by Philips.

- Nozal, a merchant in metallurgy and a subsidiary of Usinor-Sacilor Stell, is developing regional warehouses equipped with cutting machines and which are able to make daily deliveries of custom-cut steel to clients. The client orders on the eve of delivery: there is no need to maintain stocks, or to rely on merchants who deliver weekly.

Strategic Logistics: Permit An Increased Differentiation

- PSA and Renault, like many car-makers, have developed a just-intime logistics that permits them to feed very flexible production lines that are capable of assembling vehicles that conform exactly to client specifications, with synchronized and single deliveries. The Renault Clio, for instance, can be delivered with the following options: airconditioning, power-steering, 80 different engine types, 20 different gearboxes, and 5 different bodies: a total of 32,000 theoretical combinations, without taking into account the range of paintwork and upholstery options. The Peugeot 205 is available in 28,000 combinations. Over its entire automobile range, PSA can offer 500,000 combinations to its customers. The customer can even change his mind up to ten days before the delivery date, thanks to a logistics information and products system that controls its manufacturing system.

- In order to increase its range of aircraft, Airbus-Industrie elaborated a logistics system capable of supplying work stations one by one, depending on the type of aircraft being assembled.

\section{Innovation}

Logistics Strategy: Logistics As a Support for Innovation, Logistics Innovation

- La Redoute, a French mail-order firm, promises its customers a twoday delivery service which has enlarged its market. This commercial innovation depends on a very strong integration of physical and information flows and on the automation of the sorting centre created for it by the French postal service.

- In order to exchange logistics information with its suppliers (information concerning its suppliers' shipment notification, etc), the French automobile sector has set up an EDI (Galia/Odette) network, which is a genuine support for the just-in-time model of production planning.

- In order to recapture a share of the refrigerated goods market, the SNCF (French National Railwayș) operates an overnight service between the south of France and Paris with refrigerated wagons. These trains are very fast $(160 \mathrm{kph})$. They are loaded in the early evening.and arrive at the Rungis wholesale market outside Paris at dawn.

Strategic Logistics: Logistics As a Source or Motor for Innovation

- The IBM factory in Montpelier, which manufactures the large ES/ 9000 systems, has linked some of its suppliers to an EDI network. A work station can therefore make a direct request to a supplier, who then has 48 hours to deliver ( 15 per cent of factory orders are sent by this system). IBM has thus been able to reduce the duration of production cycles by 70 per cent (better reactivity), reduce costs and take full advantage of the technological innovations proposed by its suppliers, without being penalized by the obligation to use parts that are still in stock but are already obsolete. By the same token, IBM can produce tailor-made products for its customers.

- By adopting a very strong reliability-maintainability-availability approach, that depends in large part on a very efficient spare parts logistics, Bull has been able to guarantee a rate of breakdown downtime with its large systems equal to at most 2.5 hours per year.

\section{Alliance}

Logistics Strategy: Logistics as a Means of Alliance

- In negotiating a 'logistics charter' with its supplier, the PSA automobile group seeks to stabilize and perpetuate its client-supplier relations. This logistics charter identifies the rights and duties of suppliers in terms of delivery requirements transmitted by PSA factories. Members of this 'network' are interdependent to the point that in certain cases the car-maker transfers its skills to the supplier (design of new parts, quality control at the source). Some suppliers are no longer 'parts suppliers' but have become 'function suppliers' (for example, tightness supply as opposed to rubber joint supplier). 
- IBM has become an affiliate with the French transport company Calberson (IBM holds 49 per cent of the capital). This new firm, Logic-Line, has taken over the physical distribution of IBM microcomputers and has become a specialist in just-in-time delivery from completely automated warehouses.

Strategic Logistics: Logistics as a Source/Motor for Alliance

- By developing its own powerful centralized logistics system, that is dedicated to the stores operated by 'independent' members, the French distribution group Intermarche has placed them in a position of total dependence vis-à-vis the group.

- In order to set up in France, UPS (United Parcel Service) chose to buy Prost, a French parcel service that has developed very innovative technical solutions for both transport and parcel tracking.

- Tailleur Industrie, a designer and operator of advanced warehouses specialized in the synchronized delivery of parts to factories organized on a just-in-time basis, is now associated with CAT, a transport subsidiary of Renault, in order to respond to all invitations to tender made by automobile and aeronautical manufacturers.

\section{Expansion by Profession}

Logistics Strategy: Logistics as a Support for Integration

- Integrators, former messenger services (urgent letters), have become express delivery services by integrating various activities: air transport, sorting, pre- and post-routing, all of which is coordinated and followed up by a very powerful communication and information system.

- Andre, a French shoe distributor (a chain of both urban shops and specialized supermarkets), strengthened by its logistics organization, has taken over some ready-to-wear clothing chains (Kookai, Caroll, Creeks).

Strategic Logistics: Logistics as a New Product

- The Bull group, by innovating in a very efficient after-sales logistics, no longer sells machines but a complex, powerful and very reliable computation package (hardware, software, and a 24-hour technical support).

- For Otis, DEC, Dassault, Eurocopter and others, after-sales logistics has now become a product which is a source of revenue and sometimes of profits which are superior to those made when the products were originally sold.

\section{Expansion by Mission}

Logistics Strategy: Logistics as a Support for extension

- SKF, Roussel-UCLAF, IBM etc, can only ensure their internationalization by entrusting European subsidiaries with specialized factories and by including them in a complex logistics network composed of central and national warehouses that are in constant contact.

- In the same manner, it has taken a powerful logistics system to enable Renault to coordinate its two complementary factories in Douai (France) and Valladolid (Spain).

Strategic Logistics: Logistics in Order to Win New Clients/Customers

- Continent, a French hypermarket chain, supplies its new Greek stores in Salonika and Athens with the same logistics tool it uses for its stores in the South of France.

- Marks and Spencer supplies its stores in France from a logistics site in Kent.

- The organization of the Philips-Eclairage central warehouse in France could enable it to serve certain European neighbours.

\section{Diversification}

Logistics Strategy: The Use of Logistics Synergies

- Numerous road haulage firms, in all of the European countries, have become specialized logistics suppliers for special traffic or goods that present homogeneous logistics characteristics: TFE (Transport Frigorifiques Européens) for fresh products; Salvesen for frozen products; Ducros (France) and UPS (Germany) for deliveries in dense urban zones; FDS (France Distribution System), NFC and Exel Logistics (United Kingdom) for supplying large distribution chains.

- Automobile makers, with their great capacity (commercial and logistic) to mobilize the resources (industrial and technological) of their suppliers, are becoming vehicle designers (imagining more attractive combinations of components for the client) and assemblers (by just-in-time converging of everything necessary to assemble the vehicle ordered by each customer).

Strategic Logistics: Diversifying Through or in Logistics

- Through exploitation of its automated warehouse, Philips-Eclairage diversified into the creation of a parcel service that allowed it to deliver to all of its clients, large and small, everywhere in France and every day, to the point where it now sells more logistics services than electric equipment. The company has started to deliver articles made by other manufacturers, provided that they are not in direct competition with its own products.

- Telemarket, a subsidiary of the Monoprix-Galeries Lafayette distribution group, offers its customers who order by phone or Minitel (the French videotex system) home delivery by appointment. These customers are obviously different from those who shop in the Monoprix stores in city centres.

- Logic-Line, which specializes in just-in-time deliveries from highly 
automated warehouses, has diversified its services; Logic-Line Consultant develops skills in diagnostics and logistics advice, as in systems engineering and automated warehousing.

\section{Strategic Action Itineraries in Logistics?}

The above examples provide evidence that on one hand firms do not centre their strategy on logistics alone (informatics and marketing, in particular, are always implicitly if not explicitly associated) while on the other hand they do not strictly aim for a single result only (differentiation, for example). The generic strategies mentioned and separately illustrated (for convenience) in the previous section are not only dependent but are also more generally combined. Three strategic action 'itineraries' can be detected:

- The firm is aiming at a privileged axis and obtains other advantages from 'spin-offs'

- The firm deliberately aims at several axes that may be spread out in time but are conceived as being interdependent

- Once the firm has aimed at one or several strategic axes and has built a new logistics system, it discovers that it can 'rebound' and, from that point on, aim at new axes.

For each of these itineraries, which can, of course, be used linked together by firms, we present a figure setting out the various options, followed by several examples. In order to simplify the presentation, we have used the abbreviations $1 S$ (logistics strategy) and SL (strategic logistics) to identify the perspective adopted by the firm.

\section{The Possible Spin-offs From a Strategic Move}

- Andre, by expanding through professions (IS) that were in large part founded on logistics and commercial abilities, will probably endeavour to find logistics synergies in its distribution network in order to reinforce its cost domination (IS).

- Nozal first sought a differentiation (1S) in terms of its clients but then discovered that the principal advantage of its service was in reducing the costs of its clients (sL) who could then limit their inventory level and order only when necessary, without risk of stock-out.

- The technologies for tracking parcels, logistics innovation (IS) developed by a growing number of express delivery services constituted at first a differentiation approach (sL) vis-à-vis competitors (attempting to obtain a modern image, without great value in terms of exploitation). By making transfers more reliable (increased control of risks), such technologies make it possible to reduce the level of the consignee's inventory and therefore it costs (sL), while at the same time reducing production cycles (as in the case of IBM). The most dynamic express delivery services now integrate such technologies

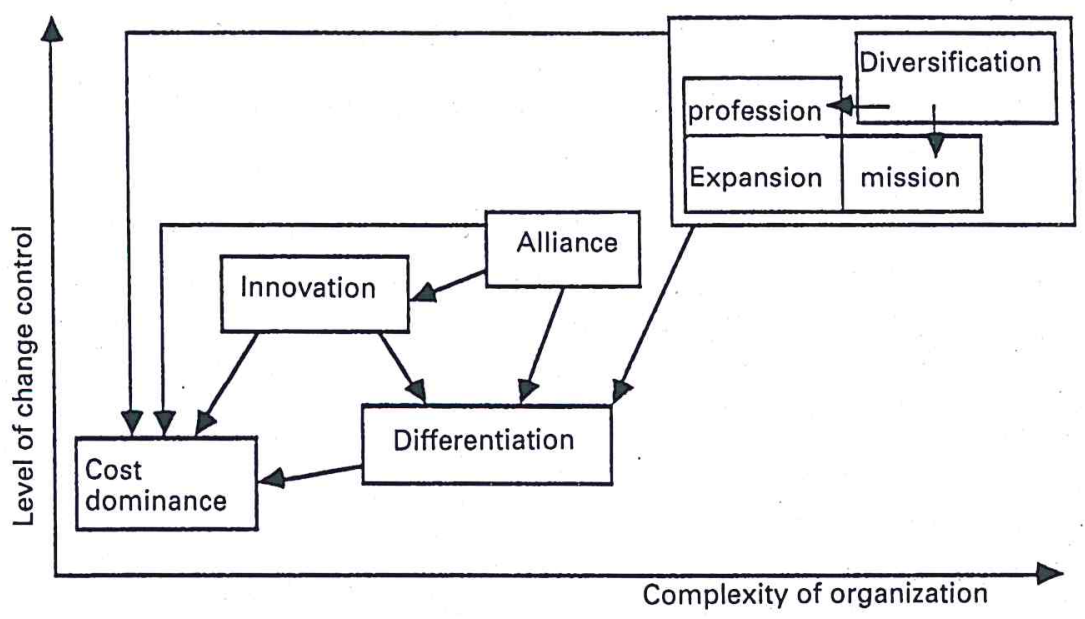

Figure 3.4 Possible spin-offs from a strategic move

into their commercial approach and thus move again by expanding their mission (sL).

It should be noted that spin-offs are always in the direction of decreasing organizational complexity and towards a lower level of change. Because spin-offs are not a priori foreseen, they are not automatic and, in any case, are of less intensity than when strategic moves are deliberately played in a combined manner.

\section{Combination of Articulated Strategic Moves}

- In distribution, the intention of a firm to equip itself with its own and/or subcontracted logistics means corresponds to a combination of deliberate logistics moves: reduction of direct logistics costs (IS) (Carrefour) and overall supply costs (sL) (Auchan and Intermarche); the will to differentiate (Auchan, with its broad range of food products, approximately three times that of Carrefour); the desire to make alliances (sL) (Intermarche) or to permit geographic expansion (sL) (Continent), or even, in certain circumstances, to open to diversification (sL) (Telemarket). Monoprix-Telemarket is an example of a firm which has more or less implemented all of these strategic dimensions, others will follow the same path.

- The IBM-Calberson joint venture, conceived on the basis of an alliance (IS), has rapidly led to a diversification approach (sL) (LogicLine).

- Integrators, with their knowledge of complementarities and alliances (sL) (UPS), have sought to integrate mobilized means (IS). Certain firms, such as DHL and TNT, offer their networks to dispatch parts between industrial sites working with the just-in-time system. This 
corresponds to a strategy of diversification (sL), when compared with their original trade.

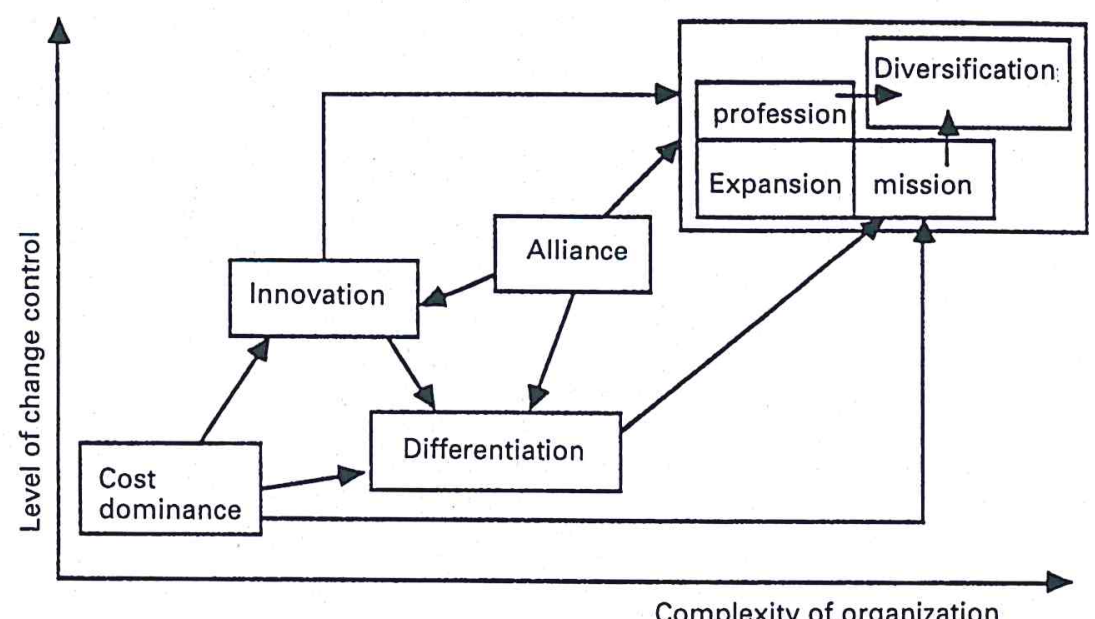

Figure 3.5 Possible combination of articulated strategic moves

This level of strategic maturity is not yet very widespread, which explains the most frequent situation where the firm rebounds by making a posteriori discoveries of new means of action.

\section{Rebounding With New Strategic Moves}

It should be noted that the possibilities illustrated in Figure 3.6 are not as numerous as those in Figure 3.5 as the moves are not intended to be linked together.

- Medis is a purchasing centre equipped with extensive logistics means (with some automated warehouses) developed jointly with several chains of food retailers (minimarkets and hypermarkets in the South of France). MEDIS is the result of an alliance founded on logistics (IS) and is now in the process of diversification (sL) by supplying a chain of 'hard discount' stores, Les Mutants, who offer some 600 products with a single 'first price reference' for each item.

- With a major investment of several hundred million francs (IS) in an automated distribution warehouse, Philips- Eclairage initially sought to differentiate itself from its competitors (IS). With its acquired experience, it then took over the distribution of materials complementary to or different from its range and made by other manufacturers. Can it be said that this diversification (sL) has transformed Philips-Eclairage into a logistics distribution firm? Where are the margins: through the sale of products or the sale of logistics services?

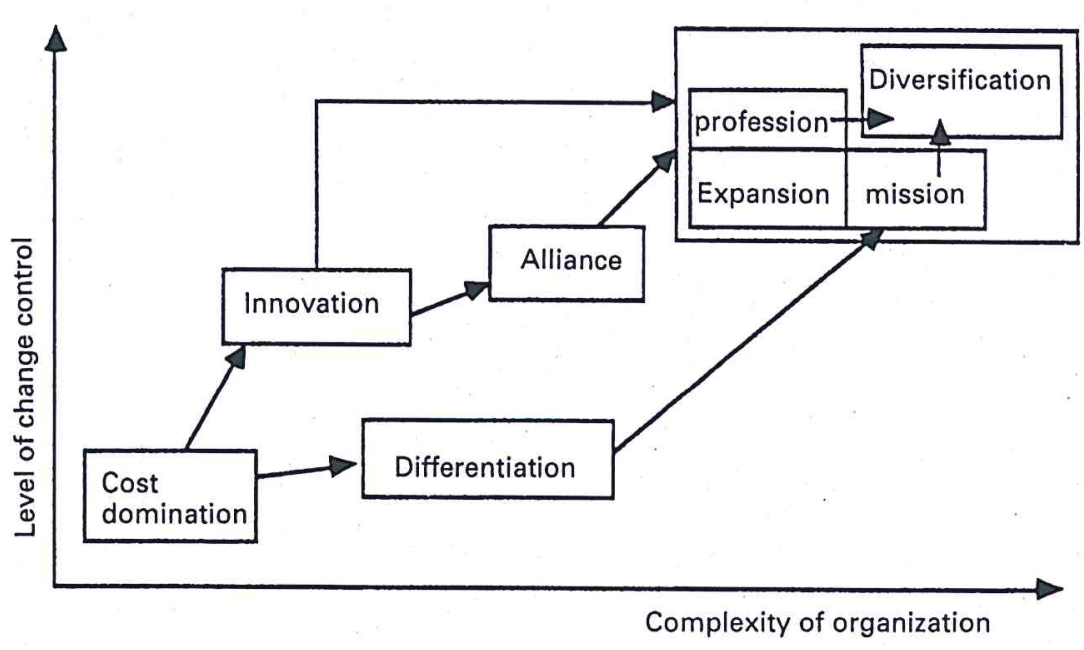

Figure 3.6 Rebounding with new strategic moves

Note that a second rebound has led the firm to geographic expansion (sL) by delivering to customers in regions beyond France.

- The automobile industry (PSA, Renault, etc) has operated a very complex combination of logistics approaches of overall cost reduction through logistics (sL), differentiation (sL), innovation in logistics EDI (1S), that go through alliances with logistics suppliers and parts suppliers (sL) and expansion by internationalization (IS). On the strategic level, starting with logistics synergies (IS), a diversification phase can lead the firm to make a radical change in paradigm. With their strong logistics skills, the car-makers are becoming conceivers and assemblers, able to offer either very differentiated ranges of cars (Clio and 205 examples), or, on the contrary, very standardized vehicles. Thus the time from conception to industrialization of the Twingo, the latest Renault model, was only 33 months, for an investment of only 3.7 billion francs. This very original car is only available in 32 combinations (options: air-conditioning, sunroof, eight body/seat colours). It is built on the same production lines as the Clio, which is available in tens of thousands of different versions. In our opinion, this constitutes a strategic logistics (sL) diversification that essentially depends on both the perfect control of logistics processes and communication and information systems.

- The logistics suppliers Tailleur-Industrie developed know-how for advanced warehouses and just-in-time synchronized industrial deliveries by first following an innovation approach (IS) and then by alliances founded on logistics (sL). It is now rebounding on diversification (sL) by proposing to its customers (car-makers) that it should perform assembly phases in its advanced warehouses for parts that it already manages. It can therefore assemble certain parts (eg bumper, lights and electrical system) and deliver them directly to the 


\section{Logistics and Distribution Planning}

production lines as required. Since it is a logistics supplier, it can become a parts supplier.

In the end, the formulation of logistics strategies is almost always extremely complex. It is the result of the interaction between two types of approach: reactive (logistics strategy, $1 \mathrm{~S}$ ) and active (strategic logistics, $\mathrm{sL}$ ). In addition, it strongly overlaps strategies formulated by other vital functions in the firm. Moreover, it is expressed by combinations of strategic moves that can either be linked or can lead the firm to rebound to new actions or finally produce spin-offs that are sometimes unexpected: there can therefore be no a priori rules for the formulation of logistics strategies.

The analysis grids proposed in this chapter show this complexity, and seem to us to be good tools for the formulation of strategies supported by or founded on logistics that can develop on several levels. From this point of view, can it not be said that logistics now constitutes a privileged area in strategic management?

\section{Summary}

- Firms formulate their strategies in response to intense environmental pressures

- Logistics is an essential element of that strategy

- The field of logistics has become progressively broader and is now very far-reaching

- A trend from the perspective of logistics strategy to that of strategic logistics is apparent, representing a source of competitive advantage

- A variety of 'classic' generic strategic axes and formulations can be identified.

\section{References}

${ }^{1}$ Morin, E., Science avec Conscience, new edition, Le Seuil-Points, Paris, 1990.

2 Martinet, A.C., Stratégie, Vuibert, Paris, 1983.

\section{Further Reading}

Ansoff, I (1979) Strategic Management, Macmillan, London.

Chandler, A D (1962) Strategy and Structure, MIT Press, Cambridge, Mass.

Mathe, H, Collin, J, Tixier, D (1983) La logistique, Dunod, Paris.

Wiseman, C (1985) Strategy and Computers, Dow Jones-Irwin Inc, USA.

\section{Chapter 4}

\section{Organizing for Logistics}

\section{Philip Schary}

Oregon State University

Logistics has been described as 'the corporate traffic cop, ${ }^{11}$ directing the flow of material and finished products from source through production and distribution to the final customer. The scope of its potential responsibility is staggering, but the ability of logistics management to take direct action is limited. This presents the fundamental problem: how to build and guide an integrated management system which spans the entire organization through the actions of other managers.

The ultimate objective of the logistics manager is to support corporate goals by delivering products to the final customer, at a time and place of their choosing. This normally means not only managing individual shipments, but a continuing series of transactions which provide genuine service to customers. Logistics service involves the taking on of tasks that the customer would otherwise perform, and creating interdependence between customer and supplier. These objectives must be balanced against the costs of providing service. The task of the logistics manager is then to direct a system involving multiple functions, organizational units and external organizations to achieve an optimal balance of service and cost.

The perspective on logistics has been shaped in recent years by three forces: the concept of the supply chain, the movement towards globalization, and the process of deintegration of industry - the 'hollowing out' of the industrial corporation. The first of these forces focuses logistics on integrating the entire set of activities in procurement, production and distribution into a single decision system. The second emphasizes that logistics has developed in a world of international markets and supply links, organized through corporations with global perspectives. The environment of logistics must take into account differing operating parameters and environmental conditions. The third is a fundamental change in the organization of industrial production. Corporations focus on their core activities, contracting for the rest from other suppliers and service organizations. This last presents both challenge and opportunity for logistics management. The challenge comes from the necessity to coordinate across organizational boundaries. The opportunity is that this is a natural extension of the traditional role of logistics management.

This chapter addresses three areas: the logistics task, organizational issues and the relationship between management and the information system. They are closely related. They are also characteristic of modern 